\title{
Design and fatigue analysis of an aluminium alloy aerodynamic wheel
}

\section{Róbert Huňady*, Michal Fabian, Pavol Lengvarský, Albert Mareš and František Kupec}

Technical University of Košice, Faculty of Mechanical Engineering, Letná 9, 04200 Košice, Slovakia

Email: robert.hunady@tuke.sk Email: michal.fabian@tuke.sk

Email: pavol.lengvarsky@tuke.sk

Email: albert.mares@tuke.sk

Email: frantisek.kupec@tuke.sk

${ }^{*}$ Corresponding author

\begin{abstract}
The deployment of CAx systems has a great influence on the design of individual car components. One of the components that must meet not only aesthetic requirements but also strict safety criteria, guarantee mechanical integrity and have good aerodynamic properties, is a car wheel. Before production begins, wheels must undergo a series of numerical analyses as well as experimental tests. Based on these tests, design modifications are made so that the wheel meets the safety criteria in real operation. The aim of this paper is to present the wheel design process, including the simulation of the rotary bending test using finite elements method (FEM). The paper describes boundary conditions of the numerical model, the process of finite element mesh generation and the results of linear static analysis and fatigue analysis of an aerodynamic wheel.
\end{abstract}

Keywords: aerodynamic wheel; wheel design; CAD model; rotary-bending test; linear static analysis; fatigue analysis; FEM; finite elements method.

Reference to this paper should be made as follows: Huňady, R., Fabian, M., Lengvarský, P., Mareš, A. and Kupec, F. (2021) 'Design and fatigue analysis of an aluminium alloy aerodynamic wheel', Int. J. Vehicle Design, Vol. 85, No. 1, pp.97-113.

Biographical notes: Róbert Huňady received his $\mathrm{PhD}$ in Applied Mechanics from the Technical University of Košice in 2010. Since 2014 he has been working as an Associate Professor at the Faculty of Mechanical Engineering. His scientific activities include structural and material research, experimental and numerical methods of mechanics, modal and vibration analysis.

Michal Fabian graduated in 1987 at the Faculty of Mechanical Engineering, Technical University of Košice in the field of Transport and Handling Technology. Since 1990, he deals with an application of the CAx systems in the processes of vehicle development and production, especially with design of car exteriors and interiors. He works as an Associate Professor at the Department of Automotive Production at the Technical University of Košice. 
Pavol Lengvarský received his Master's degree in the field of Applied Mechanics, in 2013, and a PhD in Applied Mechanics from the Technical University of Košice in 2017. His professional and scientific interests are focused on the finite element method, nonlinear mechanics, shell theory, and modelling of nanoparticle behaviour by means of classical continuum mechanics.

Albert Mareš graduated in 1994 at the Faculty of Mechanical Engineering, Technical University of Košice in the field of Innovation of Mechanical Engineering Production. At present, he works as a Professor Assistant at the Department of Automotive Production at Technical University of Košice. He is professionally specialised in CAD technologies, assembly and application of software for assembly task analysis.

František Kupec is applying for a $\mathrm{PhD}$ in Mechanical Engineering at the Institute of Technological and Materials Engineering of the Technical University in Košice. He carries out research in the field of car body shape modification to achieve the optimisation of aerodynamic properties.

\section{Introduction}

Increasingly sophisticated component design and manufacturing technologies enable technical development centres to increase the aesthetic, functional and safety requirements of vehicles and their parts, including wheels. Wheels must ensure traction and stability while the vehicle is driving to ensure not only comfortable driving, but especially the safety of the occupants.

At present, the field of design is strongly supported by computer technology. There is a lot of software with advanced modelling tools that allow to the application of various techniques and procedures to create solid or surface models (Jabczun, 2017; Fabian et al., 2017; Fabian et al., 2018). Creating 3D prototypes in a virtual environment of a CAD system has become an essential part of the component development process in the engineering, automotive, aerospace and consumer industry. In most cases, the design phase is followed by a virtual structural analysis of the proposed components, which is performed using numerical methods such as finite element method, boundary element method, finite volume method. Tests on real components are performed at the final stage of development. The experimental tests or measurements are mostly used to verify the accuracy of computer simulations, i.e., the component is primarily optimised in the virtual environment of CAx programs. Despite the increasing popularity of computer solutions, the significance of experimental analysis is not diminished in any way and plays a key role in different phases of development. In case of significant differences in the results between simulation and experimental measurement, it is necessary to re-analyse the load cases, boundary conditions and find the causes of the differences. For example, in the case of car crash tests, the experiment is crucial to confirm the accuracy of the numerical model (Zhang et al., 2008; Li et al., 2015; Gutowski et al., 2017). At some stages of development, the production of physical prototypes is declining and only virtual models are used. The computing power of HW and SW equipment makes it possible. 
The development of wheel testing methods has a rich history. Grubisic and Fischer (1984) took the view that methods for optimal wheel design should be based on the concept that the wheel sizing has to take into account the operational stresses as well as allowable stresses in different wheel conditions. Therefore, they pay attention to the issues of durability testing of the wheels. They proposed the biaxial wheel durability test machine, which provides improved simulation of operating loads and allows the entire wheel to be tested in a single procedure. Karandikar and Fuchs (1990) introduced a prototype of computer-based system, called FLIPS, for predicting the fatigue life of wheels. The system utilises linear finite element structural analysis results and is comprised of a CAD package, a finite element solver, and a fatigue life computation program. Over the following years, extensive progress has been made in the field of multi-axial fatigue analysis. This progress has enabled its wider application in component durability design. Chu (1997) proposed and examined the possibilities of applying some new approaches and criteria to assess the durability of complex structures in the ground vehicle industry.

According to Kocabicak and Firat (2001), wheels are one of the most critical components of a car, as their function is essential for human safety. They proposed a bi-axial load-notch strain approximation for proportional loading to estimate the fatigue life of a passenger car wheel during the cornering fatigue test under plane stress conditions. The proposed methodology has been implemented in a program called "metal fatigue prediction and analysis" (MFPA) that provides time and cost savings in fatigue analysis of wheels. The use of parametric or topological component optimisation is very popular in engineering practice. Advantageously, this approach can be used to design automobile wheels. Hsu and Hsu (2001) used a sequential neural network to reduce the weight of aluminium alloy wheel. By optimising the position, shape and size of the weight reduction holes, they reduced the weight of the wheel by $6.5 \%$. Colalillo and Dias (2001) presented procedures for developing a project tool that can generate parametric models of automotive wheels to be calculated using the finite elements method (FEM). The development of a parametric program that could, at the same time, control the geometry, the loading and the mesh associated with a virtual test of rotational fatigue, using the finite element method, was the main objective of their work and was successfully carried out. Yay and Ereke (2001) have proposed an approximation technique for calculating wheel life, which takes into account the dynamic wheel load arising from the road conditions. They mapped this load in the form of a so-called load spectrum. The results of the calculations were compared with experimental data. Hsu et al. (2004) described the probability model of fatigue failure prediction for aluminium disc wheels, which intends to better link the prediction using simulation results with historical test data. Mean stresses and stress amplitudes during the fatigue loading cycle obtained from FE models of already physically tested wheels are plotted in a two-dimensional plane. By comparing with historical data from the test, the failure probability contour can be drawn. Raju et al. (2007) presented the fatigue life estimation process of aluminium alloy wheel under radial fatigue loading. Their approach is based on the development of S-N curve that is determined by conducting tests at different stress levels under constant amplitude loading. It was observed from analyses that the prediction of fatigue life using FEM analysis is in close agreement with the corresponding experimental observations. 
Tirovic (2012) designed a prototype wheel carrier for a commercial vehicle. The novel design is made of aluminium and is half the weight of the original wheel. The author used FEM simulations to verify the structural strength and also to assess the heat dissipation during braking. The simulation results show that the new design improves brake cooling by up to 50\%. Zuger et al. (1997) dealt with the minimisation of the wheel mass of a hybrid ultralight vehicle. In the geometric design, the authors took into account the requirements for wheel stiffness and ease of manufacturing. Deformation and stress limits were considered as constraints in the mass minimisation process. The weight of the chosen part of the geometry was minimised by varying several parameters using CAE analysis under the assumption of gravitational, lateral and braking loads. Zhang et al. (2012) used the topology optimisation method based on variable density and the minimum compliance objective function to optimal design of the wheel spokes. Wang (2013) dealt with parametric optimisation of rim geometry with variable cross-section. He used the optimisation software Isight integrated with SolidWorks and Abaqus to achieve a lightweight wheel design. Wang et al. (2011) introduced a new efficient method for evaluating the durability of aluminium wheels, in which the fatigue life is predicted using the equivalent stress amplitude and S-N curve. The equivalent stress amplitude is calculated based on the nominal stress method by considering the effects of mean load, size, fatigue notch, surface finish and scatter factors. Since the traditional fatigue test of wheel comprising the radial and cornering fatigue tests cannot simulate the real stress state of wheel well, Wan et al. (2016) proposed a new method of simulation of biaxial wheel test and fatigue life estimation considering the effects of tyre and wheel camber. Wan et al. (2019) also examined the effect of a tyre on the $13^{\circ}$ impact test of the automotive wheel. They found that the performance of the wheels is closely related to the tyres actually used, and the tyre can not only dissipate the fractional kinetic energy but also complicate the loading conditions on spoke during the impact test.

The use of carbon fibre composites in conventional automobile manufacturing is not unusual today. It is one of the ways to effectively reduce the weight of vehicles. Although composite wheels are predominantly used in motorsport, they can also be found on premium passenger cars. Wang et al. (2016) described the design process and the strength analysis method of a long glass fibre reinforced thermoplastic (LGFT) wheel that is based on multi-objective topology optimisation under multiple design spaces and multiple loading cases. The results show that the long glass fibre reinforced thermoplastic wheel saves almost $25 \%$ of weight compared to the aluminium alloy wheel. In addition, it provides a greater safety margin. Chai et al. (2018) in their study discussed the same issue. They performed the injection moulding simulation to obtain the anisotropic material properties of the LGFT wheel. Subsequently, these properties were used in FE simulation of the bending fatigue test.

Rychlik (2018) presented the concept of a non-invasive method for assessing the wheel rim state to determine its technical status which is based on modal analysis and can be applied for tests of both new wheel rims during the quality control and used rims for passenger cars, special vehicles and slow-moving vehicles. The measured and calculated parameters serve to determine the condition of joints and to identify the cracks or loss of integrity in the wheel rim structure. 


\section{Basic approaches of car wheel shape design using CAD systems}

As mentioned in the introduction several times, the implementation of CAD tools brings besides shortening of the innovation period also the possibility of high variability of shape design in a relatively short time. Advances in computer technology and computing software allow us to analyse numerical models of simple components as well as complex assemblies relatively quickly and accurately. This approach provides designers with rapid feedback where component stiffness needs to be increased, or where the structure can be lightened. From the point of view of creating a CAD model, there will be briefly described the design of an aero shaped wheel created based on the solid body in CATIA V5-6 R2014 software (Figure 2). Figure 1 shows the initial sketch design of the wheel.

Figure 1 The initial sketch design of an aero wheel

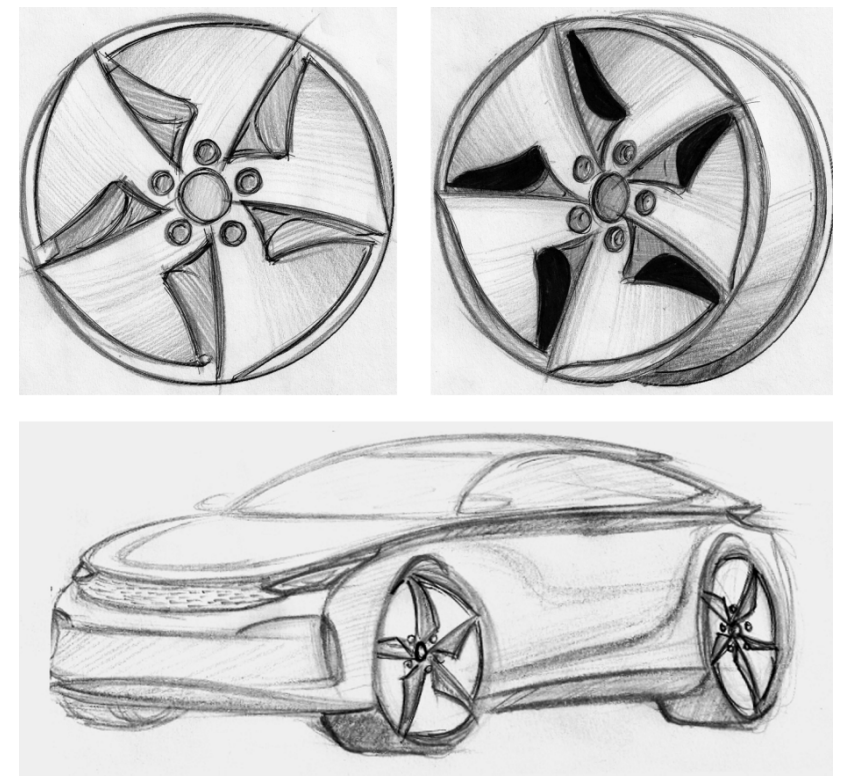

Figure 2 Procedure for creating a CAD model of the wheel (see online version for colours)
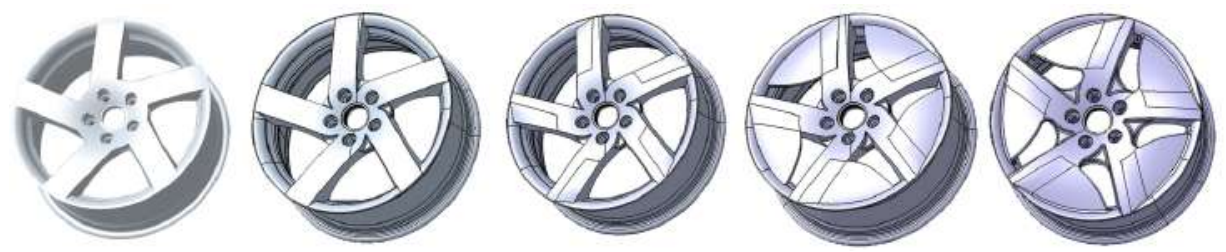

The CATIA part of the wheel consists of three separate solids: the hub, the spokes and the rim. The final shape of the wheel can be obtained using basic Boolean operations. Of course, when creating more complex shapes, it is advantageous to use the tools of the CAD surface modeller. In that case, modelling is more laborious, but the aesthetic appearance gets to a higher level (Figure 3). 
Figure 3 Surface model of the front part of the wheel (left), the final solid model of the wheel (right) (see online version for colours)
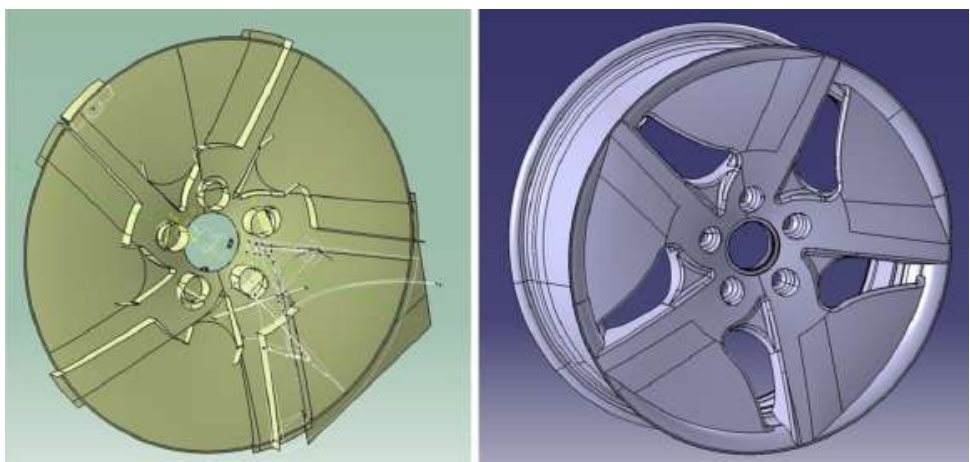

The aesthetics of the final design is assessed by visualising the wheel with the tyre or, preferably, by visualising the vehicle for which the wheel is intended (Figure 4). In the early design phases, it is common to use additive methods to create $3 \mathrm{D}$ models in a real or reduced scale. The 3D print model is used to evaluate the aesthetic aspect (Figure 5).

Figure 4 Visualisation methods of a car wheel (see online version for colours)
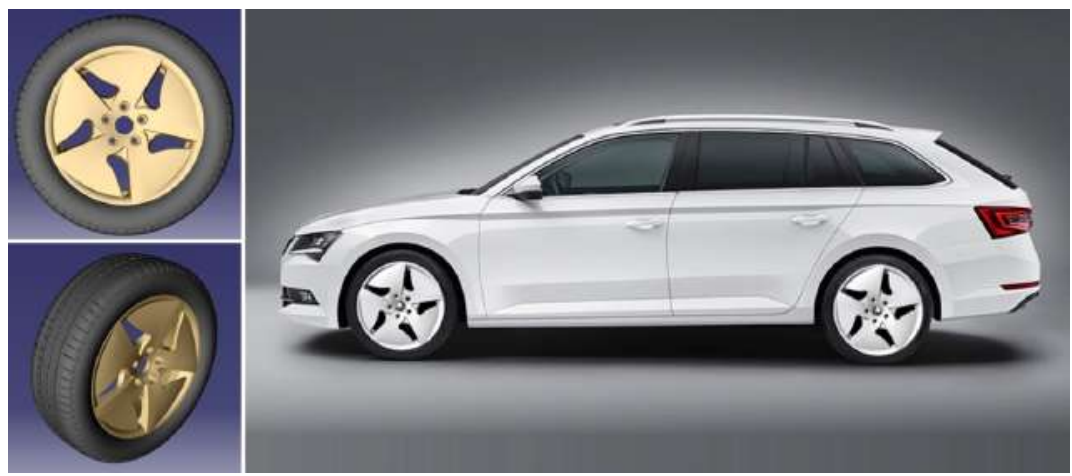

Figure 5 Data generation for production of 3D wheel model using additive printing technology (left), 3D print model of the wheel (right) (see online version for colours)
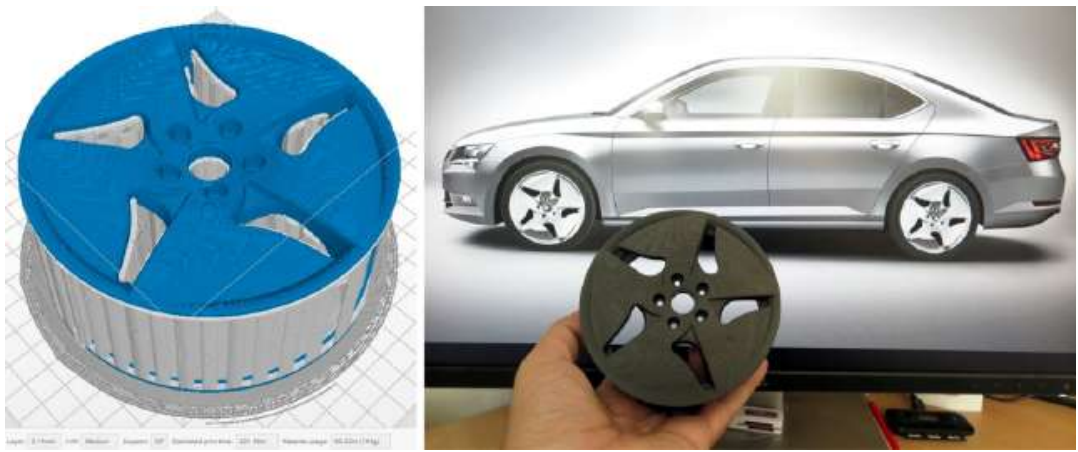
The CAD model of the wheel, created using the solid or surface modelling tools, represents the input for subsequent structural FEM analysis. Some of the universal formats such as STEP, IGES or PARASOLID can be used to transfer geometric data to the simulation program.

\section{Rotary bending test}

Fatigue tests of car wheels are governed by international standards or internal standards of car manufacturers. Rotary bending test, also known as the dynamic cornering fatigue test, simulates the loading condition on the wheel while a car is turning. Its application is aimed at the general verification of wheel suitability in the development phase. If the wheel passes this test, it has a good chance of successfully passing other durability tests, such as the dynamic radial fatigue test. The diagram of the rotary bending test rig is shown in Figure 6.

Figure 6 Diagram of the rotary bending test rig

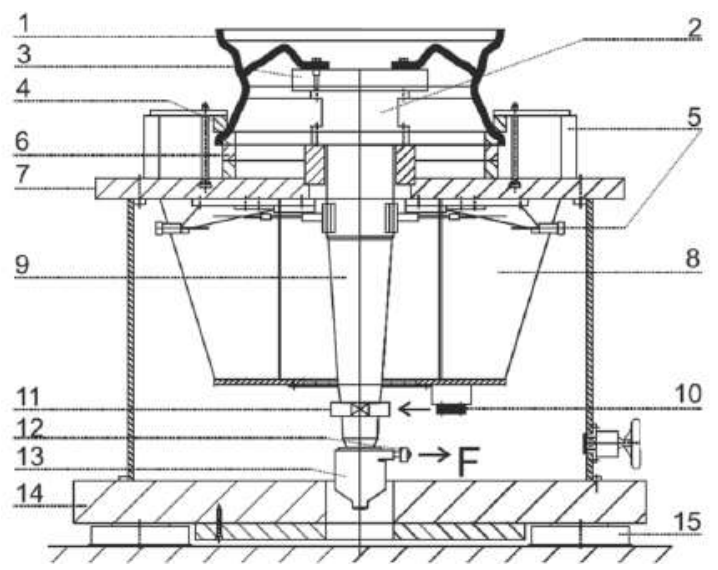

1. Wheel

2. Flange

3. Adapter

4. Clamping ring

5. Positioners

6. Distance ring

7. Mounting plate

8. Cage

9. Bending axle

10. Optical sensor

11. Rotating reflector

12. Eccentric mass

13. Electric motor

14. Base plate

15. Air suspension

The wheel must be fixed to the adapter by means of pre-loaded bolts with the prescribed tightening torque. The adapter has the same holes as the wheel hub and is attached to the flange. The flange is rigidly connected to a rod that serves as a bending axle. At the end of the rod is attached a motor with an eccentric rotor that generates a centrifugal force during rotation. This dynamic force on the axle creates a bending moment that gradually loads the wheel in all directions. The rim of the wheel is fixed to the base frame from the inside and outside by means of a pair of clamping rings.

As mentioned, the force acting on the bending axle provides a constant cyclical rotation bending moment. The bending moment $M_{b}$ is calculated as follows

$$
M_{b}=n \cdot F_{r}\left(\mu \cdot r_{d y n}+d\right),
$$

where $n$ is the strength coefficient $(-), F_{r}$ is the maximum radial load of the wheel, $\mu$ is the friction coefficient between the tyre and the road $(-), d$ is the offset of the wheel $(\mathrm{m})$, and $r_{d y n}$ is the dynamic rolling radius $(\mathrm{m})$ that is the actual radius of tyre as the vehicle moves. This takes into account the deformation of the tyre caused by the weight 
of the vehicle, as well as the centrifugal force acting on the tyre during revolutions. As a result, the free radius is reduced by approx. $3-5 \%$.

The free (geometrical) radius of the wheel is defined as follows

$$
r=\frac{D}{2}+\frac{A R \cdot W}{100}
$$

where $D$ is the rim diameter, $A R$ is the aspect ratio of the tyre, and $W$ is the tyre width (Figure 7). Then the dynamic radius will be

$$
r_{d y n} \cong 0.97 \cdot r
$$

The loading force $F_{b}$ acting on the end of the rigid bending axle is given by the following equation

$$
F_{b}=\frac{M_{b}}{\ell},
$$

where $\ell$ is the length of the axle $(0.75-0.85 \mathrm{~m})$.

Figure 7 Wheel and tyre dimensions (see online version for colours)

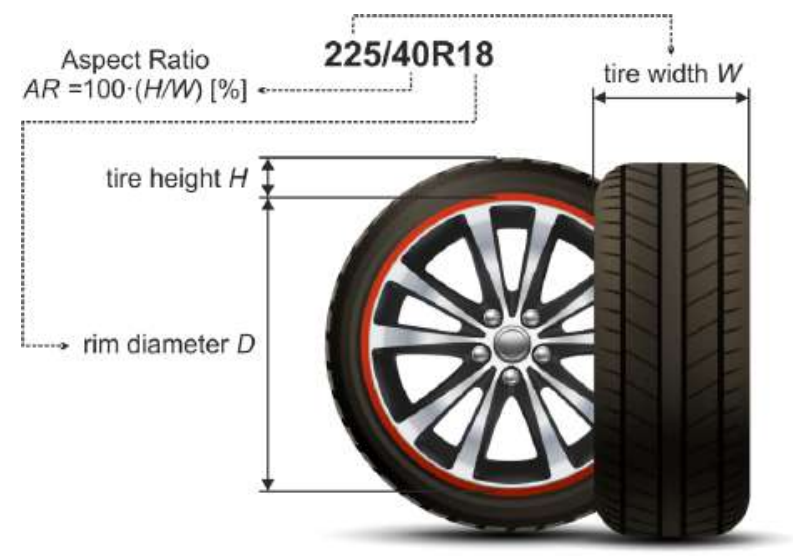

\subsection{The example of bending moment calculation}

In this study, we will design an 18-inch aero aluminium alloy wheel (Figure 3 ) labelled $8 \mathrm{~J} \times 18$ ET44 for a premium passenger car. The tyre recommended for the car is $225 / 40$ $\mathrm{R} 18$. The maximum radial wheel load is 5640 N. For the given specification:

$$
\begin{aligned}
& r=\frac{D}{2}+\frac{A R \cdot W}{100}=\frac{18 \cdot 25.4}{2}+\frac{40 \cdot 225}{100}=318.6 \mathrm{~mm}, \\
& r_{d y n} \cong 0.97 \cdot r=0.97 \cdot 318.6=309 \mathrm{~mm}, \\
& M_{b}=n \cdot F_{r}\left(\mu \cdot r_{d y n}+d\right)=2 \cdot 5640 \cdot(0.9 \cdot 0.309+0.044)=3633.3 \mathrm{Nm},
\end{aligned}
$$




$$
F_{b}=\frac{M_{b}}{\ell}=\frac{3633.3}{0.75} \simeq 4845 \mathrm{~N} .
$$

For the purpose of FEM analysis, the dynamic load is replaced by a sequence of 24 discrete steps. At each step, the direction of the loading force changes by 15 degrees. This change of direction can be achieved by dividing the applied force into two rectangular radial components $F_{b x}$ and $F_{b z}$

$$
F_{b x}=F_{b} \cdot \cos \theta, F_{b z}=F_{b} \cdot \sin \theta,
$$

where $\theta$ is the angle of application of the radial force. Figure 8 shows the dependence of the force components on the angle $\theta$.

Figure 8 Loading force and its components (see online version for colours)

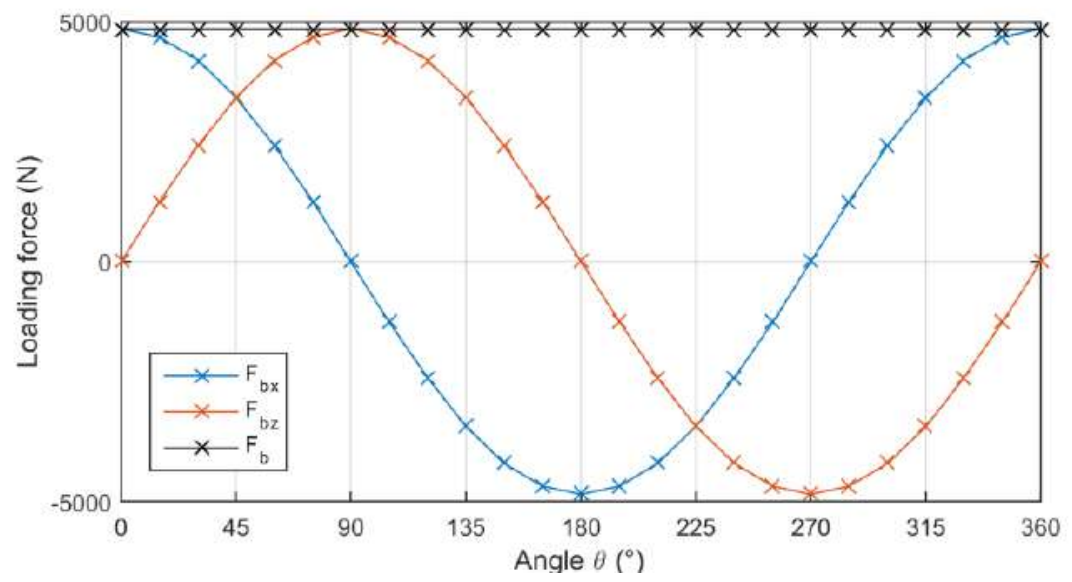

\subsection{FE model of the disc}

The first step in building the FE model is a modification of the geometry. The modification consists in simplifying the model by removing features such as small blends or fillets that do not affect the results of analysis, merging small faces into a single face, and dividing the model into multiple bodies to improve quality of the final mesh (Figure 9).

The typical danger zones of the wheel are spokes, spoke-rim junctions and spoke-hub junctions. Therefore, the mesh in these stress concentration areas should be dense. On the contrary, the parts of the wheel such as rim or barrel can be discretised by a coarse mesh. The model of the wheel was partitioned in such a way that different types of structural mesh could be used. In total, three types of solid body elements were used. Due to the shape and geometric complexity of the aesthetic part of the wheel, 10 node tetrahedral elements were used to mesh this part. The barrel was meshed using 20 node hexahedral elements. The transition between the both meshes was ensured by pyramid elements. Source element size was $4 \mathrm{~mm}$. The final mesh is shown in Figure 10. 
Figure 9 Modification of the model geometry (see online version for colours)

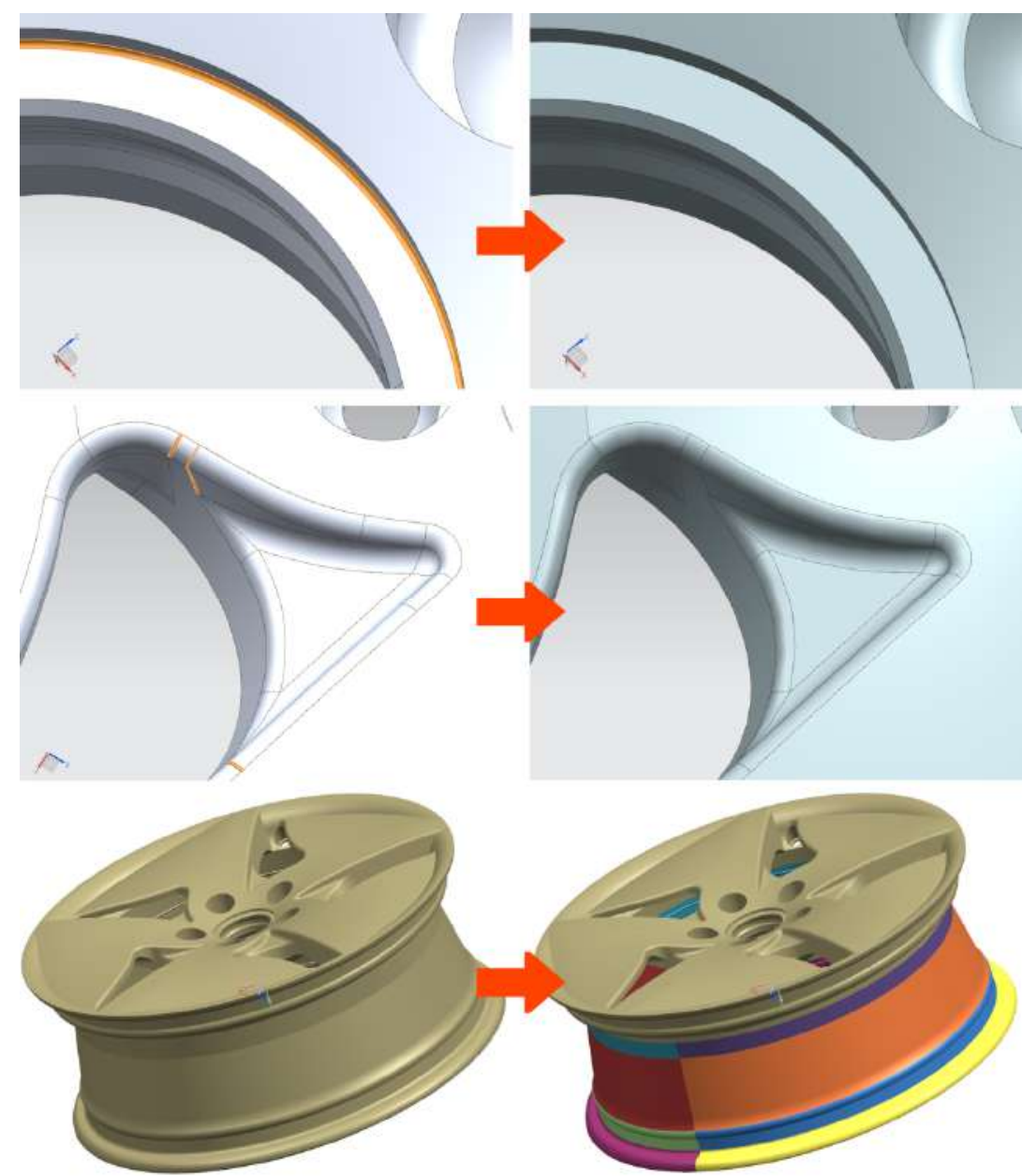

Figure 10 Meshed model of the disc (see online version for colours)
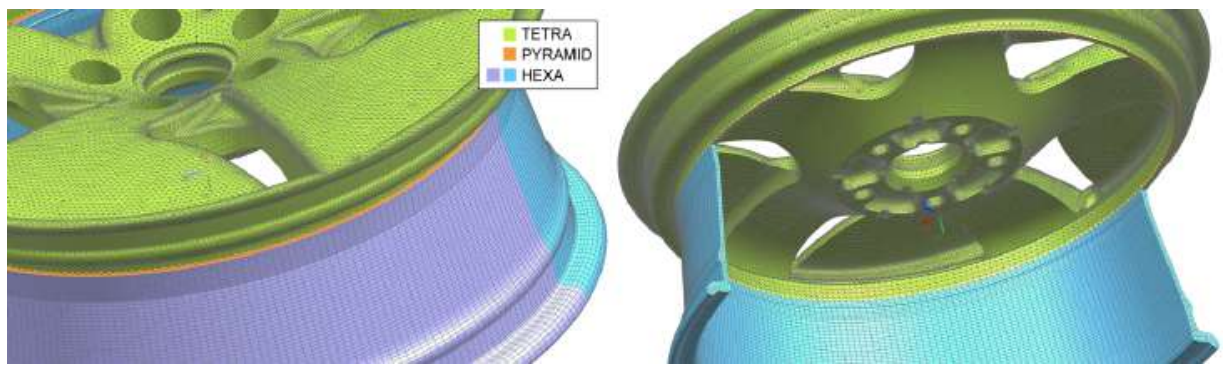

The bending axle was modelled using the rigid body elements RBE2. The elements connected the application point of the loading force with faces on the hub that are in contact with nuts (or bolt heads) and the brake disc mounting plate (see Figure 11, marked in orange). 
Figure 11 Bending axle modelled using rigid body elements (see online version for colours)
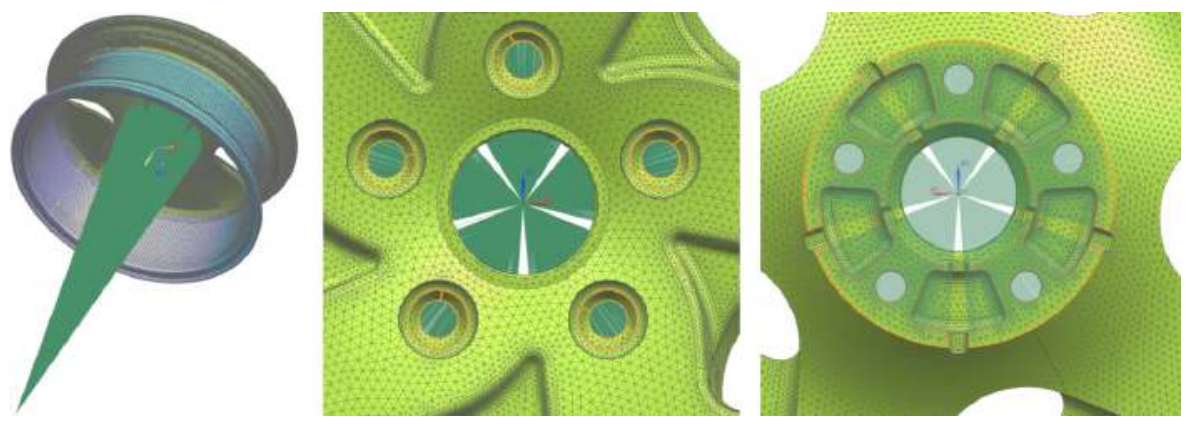

During the test, the rim is mounted between two clamping rings (inner and outer), as shown in Figure 12. This attachment is modelled using a constraint that fixes all the translational degrees of freedom of the contact surfaces nodes. The wheel is loaded by two concentrated forces $F_{\mathrm{bx}}$ and $F_{\mathrm{bz}}$ acting at the end of the bending axle. The resulting force, whose direction of action varies from 0 to $345^{\circ}$, generates the desired bending moment on the arm.

Figure 12 Boundary conditions (see online version for colours)
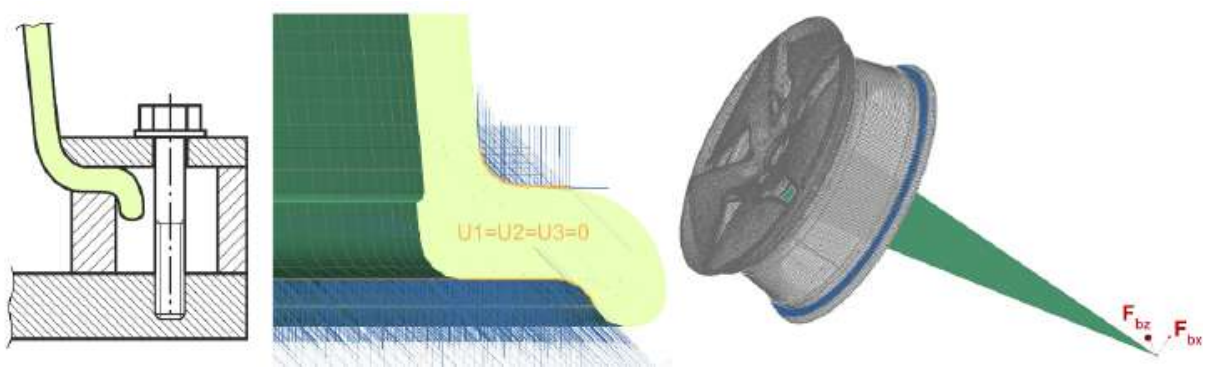

The material of the wheel was an aluminium casting alloy A356-T6, which is commonly used in the car wheels' manufacture because of its very good casting and machining characteristics. Due to its chemical composition (approx. $7 \% \mathrm{Si}, 0.3 \% \mathrm{Mg},<0.2 \% \mathrm{Fe}, \mathrm{Cu}$, $\mathrm{Ti},<0.1 \% \mathrm{Zn}, \mathrm{Mn}$ ), the alloy shows good elongation, high strength and very high ductility. Low iron content also has a positive effect on its mechanical properties. The T6 heat treatment of A356 aluminium castings offers an increase in hardness and other mechanical properties, which are often required for many applications. The material properties of the alloy A356-T6 used in FEM simulations are given in Table 1.

\subsection{Static analysis of the wheel}

The linear static analysis was performed using the Nastran iteration solver SOL 101. As mentioned above, one load cycle was divided into 24 load cases in which the direction of the bending force changes by $15^{\circ}$, while its amplitude remains constant. Figure 13 illustrates, in four selected cases, how the von Mises stress field changes. The upper limit of the values was limited to an allowable value of $100 \mathrm{MPa}$ as the maximum stress occurred at the singular points of the mesh, as shown in Figure 14(b). The singularity is 
due to the use of RBE2 elements representing the bending axle. The stress at these points exceeds the maximum allowable values. However, given the above, this can be ignored. Crucially, the stresses in critical areas of the wheel that are important for its structural integrity do not exceed this value. In these areas the stresses are significantly lower. By way of comparison, Figure 14 shows the stress field at the rear of the wheel hub for the best and the worst case load. It can be stated that the model of the wheel passed the static rotary bending test.

Table 1 Material properties of aluminium alloy A356-T6

\begin{tabular}{lc}
\hline Mass density & $2710 \mathrm{~kg} / \mathrm{m}^{3}$ \\
Young's modulus & $72,400 \mathrm{MPa}$ \\
Poisson's ratio & 0.33 \\
Yield strength & $180 \mathrm{MPa}$ \\
Ultimate tensile strength & $220 \mathrm{MPa}$ \\
Elongation at break & $<4.5 \%$ \\
Fatigue strength coefficient & $495 \mathrm{MPa}$ \\
Fatigue strength exponent & -0.117 \\
\hline
\end{tabular}

Figure 13 Von Mises stress fields on the front and rear of the wheel for four different directions of bending force (see online version for colours)

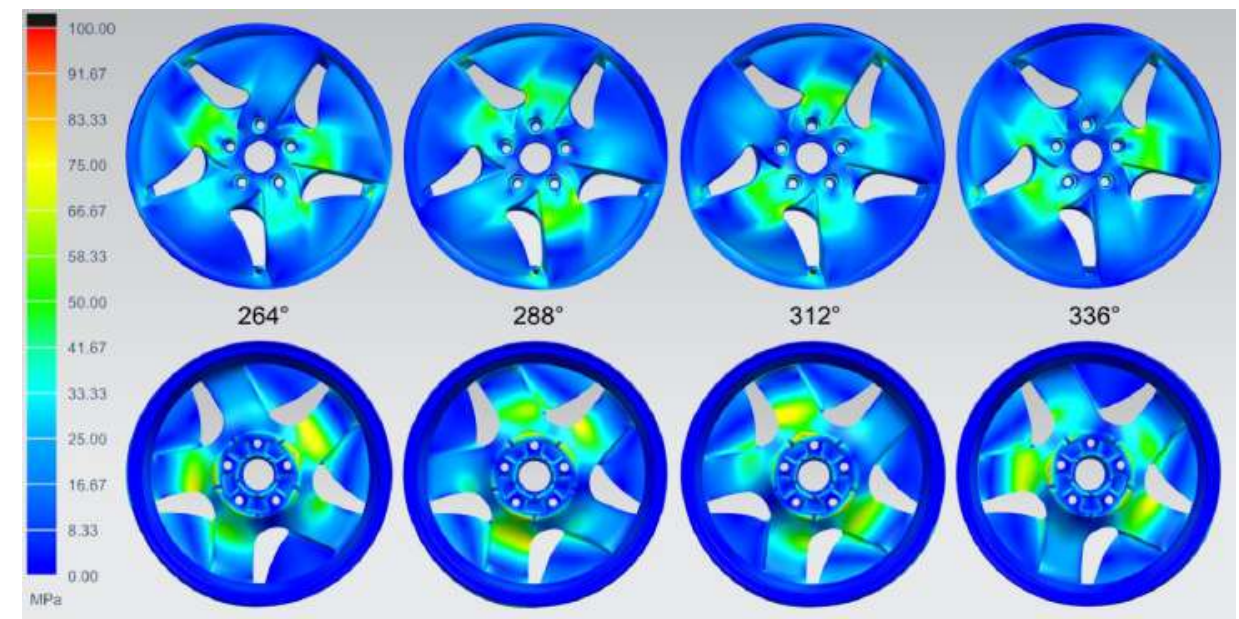

\subsection{Fatigue analysis of the wheel}

The results of the rotary bending test obtained by the linear static analysis were used in the fatigue life calculation. Fatigue is the weakening of a material caused by acting of time-varying forces (cycling loading) that results in progressive and localised structural damage and the growth of cracks. The fatigue failure of a structure occurs after a definite number of load cycles induced by the oscillating force that cause stress greater than the fatigue limit. The fatigue is the result of continuous irreversible changes within the material. These changes depend on the stress amplitude, temperature, stress state, number of cycles, and environmental conditions. The fatigue properties of materials are often 
described by the fatigue limit (or endurance limit) and S-N curve, also known as the Wöhler curve. The fatigue limit is the value of the stress amplitude below which no failure occurs, theoretically even after an infinite number of cycles. We can say that material has an infinite life. This is typical for metals such as steel, titanium and the like. Many non-ferrous metals and alloys, such as aluminium, magnesium, and copper alloys, do not exhibit well-defined endurance limits. In such cases, the fatigue strength must be specified for a given number of cycles. Therefore, it is better to describe their behaviour graphically by S-N curve. The S-N curve defines the relationship between the cyclic stress amplitude and the number of cycles to failure, i.e., $\sigma_{a}=f(N)$. Figure 15 shows the S-N curve of the A356-T6 alloy in a semi-logarithmic scale, which was determined based on a known equation

$$
\sigma_{a}=\sigma_{f}(2 N)^{b},
$$

where $\sigma_{f}$ is the fatigue strength coefficient, $b$ is the fatigue strength exponent, and $N$ is the number of cycles to failure.

Figure 14 Von Mises stress fields on the front and rear of the wheel for two different directions of bending force: (a) the best case scenario and (b) the worst case scenario (see online version for colours)
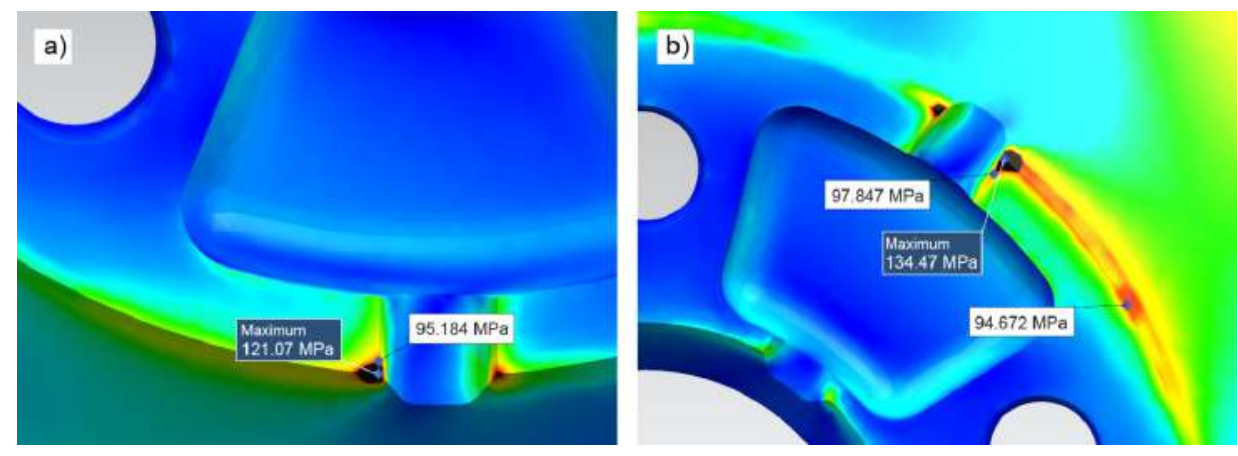

Figure 15 S-N curve of high cycle fatigue of A356-T6 alloy (see online version for colours)

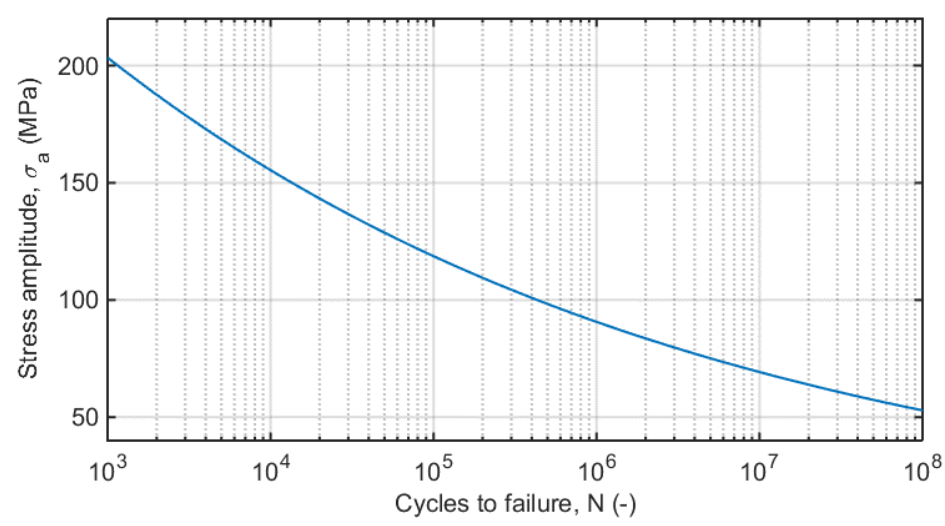

Wheel fatigue analysis was based on the stress life criterion, considering all the load cases analysed in the previous static simulation. The effect of mean stresses was included 
in the solution using the Gerber failure theory, which is suitable for ductile materials and high cycle fatigue (Lee et al., 2005; Schijve, 2009).

The condition for passing the fatigue test was that the wheel must withstand at least 200,000 cycles at $82.5 \%$ load and $1,800,000$ cycles at $55 \%$ load without any failure. The results of both analyses are shown in Figure 16. As can be seen, in the first case, the minimum fatigue life of the wheel is 353,542 cycles to failure. In the second case, its fatigue life is 8.1 million duty cycles. Based on the results of the fatigue analysis, it can be stated that the wheel model also passes the durability test.

Figure 16 Fatigue life of the wheel at $82.5 \%$ load and 55\% load (see online version for colours)
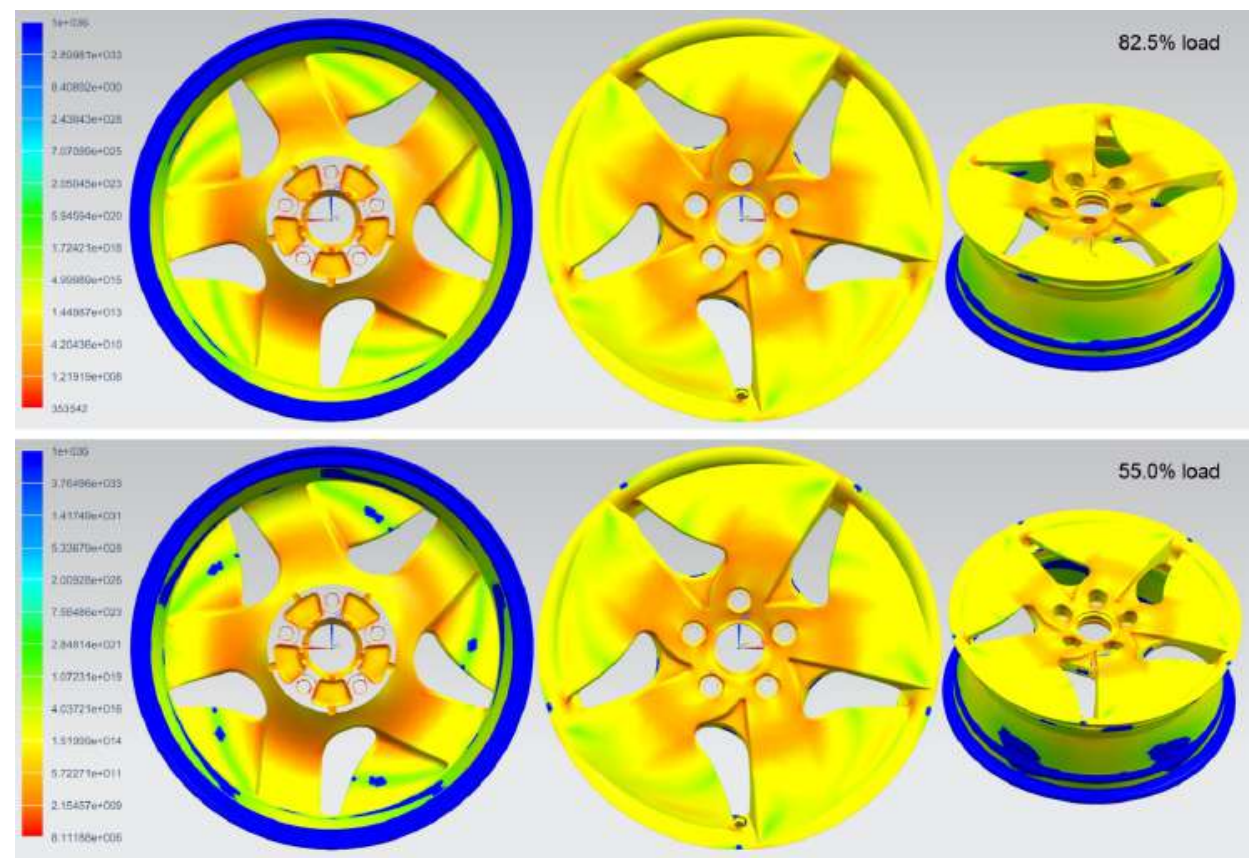

\section{Conclusion}

At present, the creation of virtual prototypes is irreplaceable in the design phase of automotive components. In the initial stages, the entire development of the car is carried out in a virtual environment using CAx applications. Before the desired state is achieved, the virtual prototype is optimised over multiple repeating loops of numerical simulations, usually followed by redesign. Usually at this stage, a component is physically manufactured and subjected to experimental tests, the results of which are correlated with the results obtained on computational models. This significantly accelerates the development phase of car design and shortens the innovation cycles. In connection with the current trends in Industry 4.0, some car manufacturers have even pursued exclusively virtual vehicle development. In this paper, the development of an aluminium wheel of a passenger car from its CAD design to the verification of its structural integrity using the 
FEM analysis was described in detail. The wheel design has been validated by the rotary bending test, which simulates the load on the wheel during standard driving. For this purpose, the linear static analysis and the fatigue life analysis were carried out using the finite element method. The static analysis was performed to determine the stress state of the wheel under the bending force acting in 24 different directions. These load cases represented the wheel load during one revolution. The magnitude of the loading force was determined based on the bending moment, which was calculated depending on the wheel and tyre parameters. According to the requirements of the test, the maximum allowable stress in the wheel must not exceed $100 \mathrm{MPa}$. The stress exceeded this value only at a few singular points of the FE mesh outside the critical area. In areas such as spokes, spoke-rim junctions and spoke-hub junctions, which can be considered crucial for strength, the stress was well below the limit. Therefore, it was concluded that the wheel passed the static test. The subsequent fatigue analysis was aimed at verifying the durability of the wheel. The analysis included wheel load within one complete revolution. This means that the result is a linear combination of the individual load cases. The durability was determined for two load levels. The condition was that the wheel withstands the prescribed minimum number of cycles $(200,000$ at $82.5 \%$ load, and $1,800,000$ at $55 \%$ ). In both cases the fatigue life was several times higher, which means that the wheel also successfully passed this test. In terms of strength and durability, the design of the wheel can therefore be considered satisfactory. In addition, the wheel weight is only $8.95 \mathrm{~kg}$. It provides an excellent strength-to-weight ratio. By topological optimisation, the weight could be reduced even further without changing the stiffness.

\section{Acknowledgements}

This work was supported by the Scientific Grant Agency of the Slovak Republic under grant VEGA 1/0110/18 "Research and development in the area of reverse engineering and rapid prototyping focused on innovations of constructional parts designed for the experimental vehicles and transport equipment" and VEGA 1/0355/18 "Use of experimental methods of mechanics for refinement and verification of numerical models of mechanical systems with a focus on composite materials".

\section{References}

Chai, W., Liu, X., Shan, Y., Wan, X. and Jiang, E. (2018) 'Research on simulation of the bending fatigue test of automotive wheel made of long glass fiber reinforced thermoplastic considering anisotropic property', Advances in Engineering Software, Vol. 116, pp.1-8.

Chu, C-C. (1997) 'Multiaxial fatigue life prediction method in the ground vehicle industry', International Journal of Fatigue, Vol. 19, Suppl. 1, pp.S325-S330(1997).

Colalillo, R. and Dias, C. (2001) Parametric Modelling of Steel Car Wheels for Finite Element Virtual Fatigue Tests, SAE Technical Paper 2001-01-4055.

Fabian, M., Puškár, M., Boslai, R., Kopas, M., Kender, Š. and Huňady, R. (2018) 'Design of experimental vehicle specified for competition shell eco-marathon 2017 according to principles of car body digitisation based on views in 2D using the intuitive tool imagine and shape CATIA V5', Advances in Engineering Software, Vol. 115, pp.413-428. 
Fabian, M., Puškár, M., Kopas, M., Kulka, J., Boslai, R., Gurbal, L., Masaryk, M., Sloboda, O. and Blistan, P. (2017) 'Principles of car body digitisation based on geometry extracted from views in 2D drawing documentation', International Journal of Vehicle Design, Vol. 74, No. 1, pp.62-79.

Grubisic, V. and Fischer, G. (1984) 'Procedure for optimal lightweight design and durability testing of wheels', International Journal of Vehicle Design, Vol. 5, No. 6, pp.659-671.

Gutowski, M., Palta, E. and Fang, H. (2017) 'Crash analysis and evaluation of vehicular impacts on W-beam guardrails placed behind curbs using finite element simulations', Advances in Engineering Software, Vol. 114, pp.85-97.

Hsu, Y-L. and Hsu, M-S. (2001) 'Weight reduction of aluminum disc wheels under fatigue constraints using a sequential neural network approximation method', Computers in Industry, Vol. 46, No. 2, pp.167-179.

Hsu, Y-L., Wang, S-G., Liu, T-C. and Hsu, M-S. (2004) 'Prediction of fatigue failures of aluminum disc wheels using the failure probability contour based on historical test data', Journal of the Chinese Institute of Industrial Engineers, Vol. 21, No. 6, pp.551-558.

Jabczun, D. (2017) Design of an Aero Wheel, Student Project, Technical University of Košice.

Karandikar, H.M. and Fuchs, W. (1990) 'Fatigue life prediction for wheels by simulation of the rotating bending test', SAE Technical Paper, 900147, https://doi.org/10.4271/900147

Kocabicak, U. and Firat, M. (2001) 'Numerical analysis of wheel cornering fatigue tests', Engineering Failure Analysis, Vol. 8, No. 4, pp.339-354.

Lee, Y., Pan, J., Hathaway, R. and Barkey, M. (2005) Fatigue Testing and Analysis (Theory and Practice), Elsevier, Vol. 416, pp., ISBN: 9780750677196.

Li, N., Fang, H., Zhang, C., Gutowski, M., Palta, E. and Wang, Q. (2015) 'A numerical study of occupant responses and injuries in vehicular crashes into roadside barriers based on finite element simulations', Advances in Engineering Software, Vol. 90, pp.22-40.

Raju, P.R., Satyanarayana, B., Ramji, K. and Babu, K.S. (2007) 'Evaluation of fatigue life of aluminum alloy wheels under radial loads', Engineering Failure Analysis, Vol. 14, No. 5, pp.791-800.

Rychlik, A. (2018) 'Wheel rim state assessment using modal and geometrical parameters', Proc. of 17th International Conference Diagnostics of Machines and Vehicles, MATEC Web of Conferences, 25-26 September, Bydgoszcz, Poland, Vol. 182, pp.1-10.

Schijve, J. (2009) Fatigue of Structures and Materials, Springer, Vol. 261, ISBN-13: 9781402068072.

Tirovic, M. (2012) 'Development of a lightweight wheel carrier for commercial vehicles', International Journal of Vehicle Design, Vol. 60, Nos. 1-2, pp.138-154.

Wan, X., Liu, X., Shan, Y., Jiang, E. and Yuan, H. (2019) 'Numerical and experimental investigation on the effect of tire on the $13^{\circ}$ impact test of automotive wheel', Advances in Engineering Software, Vol. 133, pp.20-27.

Wan, X., Shan, Y., Liu, X., Wang, H. and Wang, J. (2016) 'Simulation of biaxial wheel test and fatigue life estimation considering the influence of tire and wheel camber', Advances in Engineering Software, Vol. 92, pp.57-64.

Wang, H. (2013) 'Geometric parameters optimal design of variable cross-section rim', Lecture Notes in Electrical Engineering, Vol. 196, pp.1003-1008.

Wang, L., Chen, Y., Wang, C. and Wang, Q. (2011) 'Fatigue life analysis of aluminum wheels by simulation of rotary fatigue test', Stroj. Vestnik/Journal Mech. Eng., Vol. 57, No. 1, pp.31-39.

Wang, X., Liu, X., Shan, Y., Wan, X., Liu, W. and Pan, Y. (2016) 'Lightweight design of automotive wheel made of long glass fiber reinforced thermoplastic', Proc. of the Institution of Mechanical Engineers, Part C: Journal of Mech. Eng. Sci., Vol. 230, No. 10, pp.1634-1643. 
Yay, K. and Ereke, I. (2001) Fatigue Strength of a Rim Model with FEM using a New Approximation Technique, SAE Technical Paper 2001-01-3339.

Zhang, X., Jin, X., Qi, W. and Guo, Y. (2008) 'Vehicle crash accident reconstruction based on the analysis 3D deformation of the auto-body', Advances in Engineering Software, Vol. 39, No. 6, pp.459-465.

Zhang, Z., Jia, H., Sun, J.Y., \& Wang, M. (2012) 'Application of topological optimization on aluminum alloy automobile wheel designing', Advanced Materials Research, Vols. 562-564, pp.705-708.

Zuger, M., Josi, U. and Fuchs, A. (1997) 'Minimizing the mass of the wheel of a human-powered electro-hybrid ultralight vehicle using CAx techniques', International Journal of Vehicle Design, Vol. 18, No. 5, pp.443-441. 